\title{
Quality of Imports Relative to Exports, and the Transmission of Sustained Growth through the Terms of Trade
}

\author{
Carmen D. Álvarez-Albelo \\ Universidad de La Laguna and CREB \\ Mónica Pigem-Vigo ${ }^{\dagger}$ \\ Universitat de Barcelona and CREB
}

ABSTRACT: This paper shows that an economy can import sustained growth from abroad, in spite of not possessing mechanisms to absorb foreign technical progress. To do that, it develops a two-country model of exogenous growth with investment-specific technological change. In autarky, one country enjoys perpetual growth, while the other economy remains stagnant. In the trade situation, the terms of trade become increasingly favourable to the stagnant economy, which results in the transmission of growth. The continuous improvement in the quality of imported capital goods relative to exported consumption goods is the reason why this occurs. Moreover, countries converge in per capita income if trade is characterised by incomplete specialisation.

KEY WORDS: trade; terms of trade; quality-adjusted prices; growth transmission; convergence

JEL CLASSIFICATION: F43, O33, O41

RunNing TitLE: Transmission of Sustained Growth through the Terms of Trade

\footnotetext{
${ }^{\dagger}$ Correspondence: Departament de Teoria Económica, Escola d’Empresarials, Universitat de Barcelona, Avinguda Diagonal, 696, 08034 Barcelona, Spain. Tel. (34) 934021387; fax: (34) 934024587; e-mail: pigem@ub.edu. We are deeply indebted to Fernando Perera for his comments. We acknowledge financial support from Ministerio de Ciencia y Tecnología (SEC 2003-06080). The usual disclaimer applies.
} 


\section{Introduction}

The literature linking economic growth with international trade has mainly focused on the diffusion of technology or knowledge. To this respect, recent empirical evidence has shown that the main sources of technical change leading to productivity growth come from overseas (e.g. Coe, et. al., 1997; Keller, 2002).

As reported by Keller (2004), the literature has largely concentrated on studying technological spillovers as a mechanism of diffusion. A less developed country can directly learn from blueprints and designs that have been generated abroad, and indirectly learn from the technology embodied in imported inputs. This learning increases country’s stock of knowledge and, hence, the productivity of its inventive activity and/or of its workers. This view implies that countries possess mechanisms, as R\&D sector and/or some type of learning process, to absorb foreign technical change.

However, the result obtained by Diewert and Morrison (1986) suggests that the access to lower prices may also constitute a way of importing foreign productivity gains. More concretely, they developed an empirical model based on index numbers, and proved that an increase in the price of exports relative to imports has the same effect as an increase in total factor productivity (TFP). One could argue that, putting it simple, an improvement in the terms of trade permits to get more intermediate or capital goods by less, for instance, consumption goods. This increase in inputs raises productivity and physical capital accumulation and, hence, the growth rate of output. In this case, the existence of absorption mechanisms would not be necessary for technology diffusion to take place, since knowledge is embodied in imported goods. Embodied technical progress continuously changes goods features, making them more productive. Therefore, it causes 
the need for properly defining prices. Notice that, holding quantities constant, an improvement in the quality of imported goods relative to exported goods amounts to an improvement in the terms of trade. Thus, prices must be defined per quality or efficiency unit, instead of per quantity unit.

This paper is concerned with the international dissemination of technology in absence of any kind of absorption mechanism. More specifically, it goes further than Diewert and Morrison (1986), and poses the following question: might terms of trade movements act as the sole engine of growth for a country? An affirmative answer would imply that the effects of free trade on growth could be powerful enough to take an economy out of stagnation. A simple two-country model of exogenous growth and trade is developed to offer a theoretical answer to this question. Since the paper focuses on long run growth, the analysis is limited to the long run equilibrium.

The structure of the model is as follows. Countries produce two potentially traded final goods, capital good and consumption good, using capital and labour as factor inputs. The economies only differ in their initial endowment of capital and the quality of the capital good. More specifically, the quality of capital permanently upgrades in one of the countries (country 1), while it holds constant in the other economy (country 2). The quality of consumption good in country 1 and both goods in country 2 are identical and remain constant over time. Therefore, technological progress in country 1 is investmentspecific or embodied in capital. Thus, capital factor in the model is understood as the Solow (1960) jelly capital, and is measured in quality or efficiency units.

In autarky, country 1 enjoys permanent growth, while country 2 remains stagnant in the long run. The changes in relative quality of goods will determine the comparative 
advantage of countries. Country 1 and 2 eventually have comparative advantage in the production of capital and consumption good, respectively. The trade situation may be characterised by complete specialization of countries, or by incomplete specialization of country 1 . In either case, the terms of trade become increasingly favourable to country 2 , which results in the transmission of sustained growth. The reason is that permanent raises in the terms of trade prevent the value of the marginal productivity of capital from declining in country 2, in spite of decreasing marginal productivity of capital.

The findings also show that the omission of relative quality changes may lead to wrong conclusions when identifying the channels through which trade operates in impacting growth. If relative quality changes in the model were ignored, international relative prices per quantity unit would be considered as the terms of trade. Since these prices become constant and countries' imports and exports in quantity units permanently increase, one would conclude that trade operates via trade volume. An accurate treatment of quality would reveal that country 2's terms of trade permanently improve and, hence, that trade operates via relative prices.

Furthermore, under incomplete specialization the world economy behaves as an integrated economy, and countries converge in per capita income. Several empirical and theoretical studies have also arrived to the conclusion that free trade promotes convergence (e.g. Ben-David and Kimhi, 2004; Ben-David and Loewy, 2003). This result in these theoretical studies lies on the existence of mechanisms to absorb foreign technology. The finding from this model, however, is entirely due to movements in relative prices. 
While the improvement in the quality of goods has been already treated in the theoretical literature on growth and trade, the possibility of growth transmission through the terms of trade has been relegated to a second plane. ${ }^{1}$ The reason might be related to the results in the empirical literature indicating a deterioration of less developed countries' terms of trade (e.g. Sarkar and Singer, 1991; Hwang and Williamson, 2003). However, although this is a well-established result for these countries as a group, it fails to hold for some economies (Authokorola, 1998 and 2000). The debate on developing countries' terms of trade is not closed at all. In this regard, Athukorala (1993) emphasised the unreliability of unit value indexes as indicators of genuine price movements, since they are influenced by changes in the quality of goods. Due to the lack of suitable statistical information, researchers are restricted to using this type of index. ${ }^{2}$ Therefore, their findings refer to prices per quantity unit, and not to the "true" terms of trade.

A proper adjustment of international prices for changes in quality becomes crucial when countries trade in capital goods. A strand of the literature has found strong support for a positive effect of trade on growth through investment (e.g. Jones, 1994; Lee, 1995; Harrison, 1996). The presence of technological change embodied in capital acts

1 Several theoretical works have concentrated on analysing trade between developed economies (e.g. Rivera-Bátiz and Romer, 1991). Other studies have shown that quality upgrading in advanced economies may have the effect of leaving less developed countries out of international markets (e.g. Murphy and Shleifer, 1997; Fan, 2004). Nonetheless, this issue has been widely analysed from an empirical point of view. See, for example, Kohli (2004).

${ }^{2}$ Some public statistical agencies, as the American Bureau of Labor Statistics (BLS), have made a considerable effort in providing researchers with quality-adjusted international prices. However, these datasets do not include information for less developed countries. 
amplifying this positive effect. Recent empirical studies have found a contribution of investment-specific technical progress to TFP as high as sixty per cent (Greenwood et al.,1997; Cummins and Violante, 2002; Sakellaris and Wilson, 2004). In light of these findings, the transmission of sustained growth through the terms of trade seems more than just a theoretical possibility. Of course, a rigorous empirical analysis is needed to determine to what extent the type of phenomenon described here has taken place in less developed economies.

The remainder of this paper is organised as follows. Section 2 describes the model and outlines agent's decisions. Section 3 characterises the autarky equilibrium. Section 4 analyses the trade situation. Section 5 summarises and concludes. Lastly, three appendixes contain some details on calculations.

\section{The Model and Agents' Decisions}

This section describes the basic structure of the model and outlines agents' decisions.

\subsection{The Environment}

The world economy is modelled as consisting of two large countries, $i=1,2$. Time is continuous and endless. There are two types of agents: firms and households. As it is usual, agents have perfect foresight. All markets in both economies are competitive, and international factor flows are not allowed. Each country produces two potentially traded final goods: a consumption good, and a capital good.

Countries are inhabited by a continuum of identical households that is normalised to one. There is no population growth. Households are endowed with one unit of time at every period that can only be allocated to work. These assumptions imply that the 
population amounts to the labour force of the economies, and that variables are expressed in per capita terms.

\section{Capital and Consumption Good Sectors}

Each sector is composed of a continuum of measured one of identical firms. The next expression summarizes the assumptions on production technologies:

$$
\begin{array}{ll}
\text { Capital Good Sector } & \text { Consumption Good Sector } \\
y_{k}^{i}(t)=\left(\tilde{k}_{k}^{i}(t)\right)^{\varphi}\left(l^{i}(t)\right)^{1-\varphi}, & y_{c}^{i}(t)=\left(\tilde{k}_{c}^{i}(t)\right)^{\varphi}\left(1-l^{i}(t)\right)^{1-\varphi}, \\
\tilde{y}_{k}^{i}(t)=\tilde{q}_{k}^{i}(t) y_{k}^{i}(t), & \tilde{y}_{c}^{i}(t)=\tilde{q}_{c}^{i}(t) y_{c}^{i}(t), \\
\tilde{q}_{k}^{1}(t)=e^{\gamma t} \gamma>0, \tilde{q}_{k}^{2}(t)=1, & \tilde{q}_{c}^{1}(t)=\tilde{q}_{c}^{2}(t)=1, \\
\varphi \in(0,1), i=1,2 . &
\end{array}
$$

From now on, sub-indexes $k$ and $c$ will denote variables referred to capital and consumption good sector, respectively. Quality is embodied in goods and, hence, the difference between physical or quantity units and quality or efficiency units matters. The wiggle symbol $(\sim)$ will indicate that the variable is measured in quality units.

The quantities of capital and consumption good in country $i$ at time $t, y_{k}^{i}(t)$ and $y_{c}^{i}(t)$, are produced with constant returns to scale Cobb-Douglas technologies. The production functions use capital, $\tilde{k}_{k}^{i}(t)$ and $\tilde{k}_{c}^{i}(t)$, and labour, $l^{i}(t)$ and $1-l^{i}(t)$, as factor inputs. Factor intensities are assumed to be the same across sectors. The production of goods in quality units or quality-adjusted output, $\tilde{y}_{k}^{i}(t)$ and $\tilde{y}_{c}^{i}(t)$, comes from multiplying quality indexes $\tilde{q}_{k}^{i}(t)$ and $\tilde{q}_{c}^{i}(t)$ by the respective quantities. 
In country $1 \tilde{q}_{k}^{1}(t)$ grows at an exogenous rate $\gamma$ at each period, while $\tilde{q}_{c}^{1}(t), \tilde{q}_{k}^{2}(t)$ and $\tilde{q}_{c}^{2}(t)$ remain constant over time and take the same value that is normalised to the unit. Therefore, measurement units will only be relevant for the capital good, since the rest of quality indexes are set equal to one. These assumptions imply that technical change in country 1 is embodied in capital, and that there is no technological progress in country 2.

The difference between quantity and quality also matters for defining relative prices of goods. In both countries the price of a quality unit of consumption good is taken as numerary. ${ }^{3}$ The price of a physical unit of capital at $t$ is denoted by $p^{i}(t)$, while one quality unit of capital costs $\bar{p}^{i}(t)$ units of consumption good. The relationship between these prices is:

$$
\begin{aligned}
& p^{1}(t)=\tilde{q}_{k}^{1}(t) \bar{p}^{1}(t) \rightarrow \bar{p}^{1}(t)=\frac{p^{1}(t)}{e^{\gamma t}}, \\
& p^{2}(t)=\bar{p}^{2}(t) .
\end{aligned}
$$

In the trade situation super-index $i$ in prices will disappear, since they will be determined in international markets.

At each $t$, firms receive income from sales and pay wages and investment costs. Thus, net cash flows (NCFs) of firms are $N C F_{k}^{i}(t)=p^{i}(t) y_{k}^{i}(t)-p^{i}(t) I_{k}^{i}(t)-w^{i}(t) l^{i}(t)$ and $N C F_{c}^{i}(t)=y_{c}^{i}(t)-p^{i}(t) I_{c}^{i}(t)-w^{i}(t)\left(1-l^{i}(t)\right)$, where $I_{k}^{i}(t)$ and $I_{c}^{i}(t)$ are capital good demands measured in physical units (gross physical investment), and $w^{i}(t)$ represents 
the rental rate of labour or wage. It is assumed that firms have a fixed number of equity shares outstanding that is normalised to one, and that NCFs are paid out as dividends to the shareowners. ${ }^{4}$ Therefore, the market values of firms at time zero or prices per share at time zero, $\Pi_{k}^{i}(0)$ and $\Pi_{c}^{i}(0)$, are equal to present values of $N C F s$ between times zero and infinity, discounted at the market rate of return or interest rate $r^{i}(t)$. Hence, firms in country $i$ seek to maximize:

$$
\begin{aligned}
& \Pi_{k}^{i}(0)=\int_{0}^{\infty} e^{-\int_{0}^{i} r^{i}(\tau) d \tau}\left(p^{i}(t) y_{k}^{i}(t)-p^{i}(t) I_{k}^{i}(t)-w^{i}(t) l^{i}(t)\right) d t, \\
& \Pi_{c}^{i}(0)=\int_{0}^{\infty} e^{-\int_{0}^{i} r^{i}(\tau) d \tau}\left(y_{c}^{i}(t)-p^{i}(t) I_{c}^{i}(t)-w^{i}(t)\left(1-l^{i}(t)\right)\right) d t .
\end{aligned}
$$

The interest rate will turn out to be the rate of return to shareowners. Equities issued by firms in capital and consumption good sectors are perfectly substitute and, consequently, they must have the same rate of return.

The capital factor in the model is understood as the Solow (1960) jelly capital, which is measured in quality units. As shown by Hulten (1992), jelly capital can be expressed as $\tilde{k}_{k}^{i}(t)=\tilde{Q}^{i}(t) k_{k}^{i}(t)$ and $\tilde{k}_{c}^{i}(t)=\tilde{Q}^{i}(t) k_{c}^{i}(t)$, where $\tilde{Q}^{i}(t)$ is the average embodied technical efficiency, and $k_{k}^{i}(t)$ and $k_{c}^{i}(t)$ are capital stocks measured in physical units (physical capital). Physical capital accumulates with physical investment, while the

\footnotetext{
${ }^{3}$ The price of a quantity unit of consumption good can also be considered as numerary, since a quality unit amounts to one physical unit.

${ }^{4}$ This set-up is similar to that in Barro and Sala (1995: 120). Negative dividends are allowed, so the setup is well defined.
} 
accumulation of jelly capital depends on investment in quality units, $\tilde{I}_{k}^{i}(t)=\tilde{q}_{k}^{i}(t) I_{k}^{i}(t)$ and $\tilde{I}_{c}^{i}(t)=\tilde{q}_{k}^{i}(t) I_{c}^{i}(t)$. Thus, the motion laws of capital in country $i$ take the form:

$$
\begin{aligned}
& \dot{\tilde{k}}_{k}^{i}(t)=\tilde{q}_{k}^{i}(t) I_{k}^{i}(t)-\delta \tilde{k}_{k}^{i}(t), \\
& \dot{\tilde{k}}_{c}^{i}(t)=\tilde{q}_{k}^{i}(t) I_{c}^{i}(t)-\delta \tilde{k}_{c}^{i}(t),
\end{aligned}
$$

where the stock of capital depreciates at the same rate $\delta>0$ in both countries and sectors. Here and throughout the paper, the dot over a variable denotes derivative respect to time. In a trade situation, quality indexes in the above expression will depend on whether the capital good was produced in country 1 or 2 .

\section{Households}

Countries do not differ regarding preferences. Each household in country $i$ derives utility of the consumption and maximizes its intertemporal utility discounted at the positive rate $\rho:^{5}$

$$
U^{i}(0)=\int_{0}^{\infty} e^{-\rho t} \frac{\left(\tilde{q}_{c}^{j}(t) c_{j}^{i}(t)\right)^{1-\sigma}}{1-\sigma} d t, \sigma>0, \tilde{q}_{c}^{j}(t)=1, i, j=1,2
$$

where $c_{j}^{i}(t)$ denotes household's demand in country $i$ of consumption good produced in country $j$. The consumption in the utility function is measured in quality units. However, since quality index of consumption good equals one, this difference becomes irrelevant. Notice that in a trade situation household's consumption might become the sum of two demands.

\footnotetext{
${ }^{5}$ Current utility defines as $u\left(c_{j}^{i}(t)\right)=\ln \left|c_{j}^{i}(t)\right|$ if $\sigma=1$.
} 
At each time period the representative household receives capital income and labour income, and faces the budget constraint:

$$
\dot{a}^{i}(t)=r^{i}(t) a^{i}(t)+w^{i}(t)-c_{j}^{i}(t), i, j=1,2
$$

where $a^{i}(t)$ represents wealth, which will turns out to be equal to the sum of market values of firms in capital and consumption good sectors. At time zero, each household is endowed with $\tilde{k}^{i}(0)>0$ quality units of physical. Thus, the value of the initial endowment of capital constitutes household's initial wealth:

$$
\begin{aligned}
& \tilde{k}^{i}(0)>0 \text { given, } \\
& a^{i}(0)=\vartheta^{1}(0) \tilde{k}^{i}(0), i=1,2,
\end{aligned}
$$

where $\vartheta^{i}(0)$ is the price of one quality unit of capital owned by households at time zero.

\subsection{Agents' Decisions}

This subsection describes agents' decisions that correspond to the autarky situation. Section 4 will indicate the modifications that agents' decisions experience when the economies are in the trade situation.

Firms in Capital Good Sector

The problem of the representative firm in country $i$ consists of maximising (3) subject to (5). The first order conditions of the problem are expression (5) and:

$$
\begin{gathered}
w^{i}(t)=(1-\varphi) p^{i}(t)\left(\tilde{k}_{k}^{i}(t)\right)^{\varphi}\left(l^{i}(t)\right)^{-\varphi}, \\
-e^{-\int_{0}^{t} r^{i}(\tau) d \tau} p^{i}(t)+\lambda_{k}^{i}(t) \tilde{q}_{k}^{i}(t)=0,
\end{gathered}
$$




$$
\dot{\lambda}_{k}^{i}(t)=-e^{-\int_{0}^{i} r^{i}(\tau) d \tau} \varphi p^{i}(t)\left(\tilde{k}_{k}^{i}(t)\right)^{\varphi-1}\left(l^{i}(t)\right)^{1-\varphi}-\lambda_{k}^{i}(t) \delta
$$

where $\lambda_{k}^{i}(t)$ is the current Lagrangian multiplier. In addition, the transversality condition $\lim _{t \rightarrow \infty} \lambda_{k}^{i}(t) \tilde{k}_{k}^{i}(t)=0$ must be satisfied.

Firms in Consumption Good Sector

Similarly, the firm's problem in country $i$ consists of maximising (4) subject to (6). The first order conditions of the problem are expression (6) and:

$$
\begin{gathered}
w^{i}(t)=(1-\varphi)\left(\tilde{k}_{c}^{i}(t)\right)^{\varphi}\left(1-l^{i}(t)\right)^{-\varphi}, \\
-e^{-\int_{0}^{t} r^{i}(\tau) d \tau} p^{i}(t)+\lambda_{c}^{i}(t) \tilde{q}_{k}^{i}(t)=0, \\
\dot{\lambda}_{c}^{i}(t)=-e^{-\int_{0}^{t} r^{i}(\tau) d \tau} \varphi\left(\tilde{k}_{c}^{i}(t)\right)^{\varphi-1}\left(1-l^{i}(t)\right)^{1-\varphi}-\lambda_{c}^{i}(t) \delta,
\end{gathered}
$$

where $\lambda_{c}^{i}(t)$ is the current Lagrangian multiplier. The solution of the problem must also satisfy the transversality condition $\lim _{t \rightarrow \infty} \lambda_{c}^{i}(t) \tilde{k}_{c}^{i}(t)=0$.

\section{Households}

The representative household in country $i$ maximises (7) subject to (8) and the initial endowment in (9). The first order conditions of the problem are (8) and:

$$
\begin{gathered}
\left(c_{j}^{i}(t)\right)^{-\sigma}-\mu^{i}(t)=0, \\
\dot{\mu}^{i}(t)=\mu^{i}(t)\left(\rho-r^{i}(t)\right),
\end{gathered}
$$


where $\mu^{i}(t)$ is the discounted Lagrangian multiplier. The solution of the problem has also to satisfy that $\lim _{t \rightarrow \infty} e^{-\rho t} \mu^{i}(t) a^{i}(t)=0$.

\section{The Autarky Situation}

The next two subsections solve for the autarky equilibrium in each country. The competitive equilibrium is a set of allocations and prices that satisfy firms and households' problems, and that clear all markets in each economy. More concretely, the equilibrium in consumption and capital good markets requires that $y_{c}^{i}(t)=c^{i}(t)$ and $y_{k}^{i}(t)=I_{k}^{i}(t)+I_{c}^{i}(t)$. Appendix A contains the details on the calculations.

\subsection{Autarky Equilibrium of Country 1}

Two equivalent expressions for interest rate are obtained after some manipulation of (11), (12), (14) and (15). The equalization of these two expressions permits to write the relative price per physical unit as:

$$
\left.\begin{array}{l}
r^{1}(t)=\varphi \tilde{q}_{k}^{1}(t) \frac{y_{k}^{1}(t)}{\tilde{k}_{k}^{1}(t)}-\delta+\frac{\dot{\bar{p}}^{1}(t)}{\tilde{p}^{1}(t)} \\
r^{1}(t)=\varphi \frac{\tilde{q}_{k}^{1}(t)}{p^{1}(t)} \frac{y_{c}^{1}(t)}{\tilde{k}_{c}^{1}(t)}-\delta+\frac{\dot{\bar{p}}^{1}(t)}{\tilde{p}^{1}(t)}
\end{array}\right\} \rightarrow p^{1}(t)=\left(\frac{\tilde{k}_{c}^{1}(t)}{\tilde{k}_{k}^{1}(t)}\right)^{\varphi-1}\left(\frac{1-l^{1}(t)}{l^{1}(t)}\right)^{1-\varphi} .
$$

The market rate of return in (18) includes net marginal productivity of capital and the change in the price per quality unit. The factor allocation among sectors can be obtained from expressions (10), (13) and (18):

$$
\kappa^{1}(t) \equiv \frac{\tilde{k}_{k}^{1}(t)}{\tilde{k}^{1}(t)}, 1-\kappa^{1}(t) \equiv \frac{\tilde{k}_{c}^{1}(t)}{\tilde{k}^{1}(t)} \rightarrow \kappa^{1}(t)=l^{1}(t), 1-\kappa^{1}(t)=1-l^{1}(t)
$$


where total capital of the economy is equal to the sum of firms' capital in both sectors, that is, $\tilde{k}^{1}(t)=\tilde{k}_{k}^{1}(t)+\tilde{k}_{c}^{1}(t)$.

Country 1's autarky prices come from introducing the results in (19) in the relative price in (18):

$$
p^{1}(t)=1, \bar{p}^{1}(t)=\frac{1}{e^{\gamma t}} \forall t
$$

Therefore, one physical unit of capital costs one unit of consumption good, while the price of one quality unit of capital strictly decreases over time.

The factor allocation in (19) and autarky prices permit to write the interest rate in (18) in terms of total capital:

$$
r^{1}(t)=e^{\gamma t}\left(\tilde{k}^{1}(t)\right)^{\varphi-1}-\delta-\gamma
$$

The long run equilibrium of country 1 is characterised by a balanced growth path (BGP), in which capital and consumption grow at a constant rate, and proportions $\kappa^{1}(t)$ and $l^{1}(t)$ remain constant over time. From now on, the omission of time in variables will denote stationary values over the BGP.

A constant growth rate for consumption requires that interest rate holds constant. Looking at (21) and (1), it follows that capital and the production of capital in quality units grow at a higher rate, $\theta$, than consumption and the production of capital in physical units, $\varphi \theta$ :

$$
\theta=\frac{\gamma}{1-\varphi}, \quad \theta=\theta_{\tilde{k}}^{1}=\theta_{\tilde{y}_{k}}^{1}, \varphi \theta=\theta_{c}^{1}=\theta_{y_{k}}^{1}
$$


Technical change embodied in capital influences the growth of $\tilde{y}_{k}^{1}(t)$ in three ways. An increase in $q_{k}^{1}(t)$ directly raises output $(\gamma)$, but also increases $\tilde{Q}^{1}(t)$ and consequently output $(\varphi \gamma)$. Lastly, an increase in $q_{k}^{1}(t)$ increases physical investment and hence physical capital and output $\left(\varphi^{2} \gamma /(1-\varphi)\right)$. The impact on the growth of $y_{k}^{1}(t)$ and $y_{c}^{1}(t)$ only includes the two last effects.

Interest rate at long run derives from the Euler equation governing consumption evaluated over the BGP. Considering expressions (16), (17), (21) and (22), interest rate at long run results to be $r^{1}=\sigma \theta_{c}^{1}+\rho$. The resources allocation over the BGP can be obtained from capital accumulation (adding up (5) and (6)), the Euler equation, and (21) and (22):

$$
\kappa^{1}=l^{1}=\frac{\varphi\left(\theta_{k}^{1}+\delta\right)}{r^{1}+\delta+\gamma}=\frac{\varphi(\gamma+(1-\varphi) \delta)}{\sigma \varphi \gamma+(1-\varphi)(\rho+\delta+\gamma)} .
$$

In both sectors, an additional unit of capital yields the marginal productivity of capital $\left(r^{1}+\delta+\gamma\right)$. According to decisions on consumption and saving, a part $\varphi\left(\theta_{k}^{1}+\delta\right)$ of such additional unit is allocated to capital good sector, while the rest is allocated to the production of consumption good.

\subsection{Autarky Equilibrium of Country 2}

The autarky equilibrium of country 2 immediately follows from country 1's, since the only difference is $\gamma=0$. Therefore, country 2's autarky prices both per quantity and per quality unit are constant: 


$$
p^{2}(t)=\bar{p}^{2}(t)=1 \forall t
$$

From the expression of interest rate in equilibrium, $r^{2}(t)=\left(\tilde{k}^{2}(t)\right)^{\varphi-1}-\delta$, it is clear that the long run equilibrium of country 2 is a steady state in which all variables hold constant through time. Thus, this economy does not enjoy sustained growth. The interest rate in steady state equals the discount rate of utility, $r^{2}=\rho$, and the proportion of capital and labour allocated to the capital production is equal to $\kappa^{2}=l^{2}=\varphi \delta /\left(r^{2}+\delta\right)$.

\section{The Free Trade Situation}

Capital goods produced by countries are not homogeneous. A physical unit of capital produced in country 1 embodies more quality units than one unit generated in country 2 . Therefore, the comparative advantage of countries must be determined by the comparison of relative prices per quality unit of capital. To this respect, expressions (20) and (24) clearly demonstrate that country 1 and 2 have comparative advantage in the production of capital and consumption good, respectively.

The next step is to show that the trade situation in the long run may be characterised by either complete specialization or incomplete specialization of country 1 . Some technical details can be found in Appendixes B and C.

\subsection{Trade Equilibrium under Complete Specialization}

Under complete specialization resources of country 1 and 2 are entirely allocated to capital and consumption good sectors, respectively. Accordingly, firm's problem in consumption and capital good sector does not apply for country 1 and 2, respectively. 
The competitive equilibrium of the world economy implies that a part of capital good production is exported to country 2 and the rest is used within country 1 , $y_{k}^{1}(t)=I_{k}^{1}(t)+I_{c}^{2}(t)$. Similarly, a part of consumption good production is exported to country 1, while the remaining production is consumed within country 2, $y_{c}^{1}(t)=c_{2}^{1}(t)+c_{2}^{2}(t)$. Moreover, the trade balance must be always in equilibrium, $p(t) I_{k}^{2}(t)=c_{2}^{1}(t)$. The last equilibrium condition can be rewritten in terms of the exported-imported proportions of goods by countries as:

$$
1-u(t) \equiv \frac{I_{c}^{1}(t)}{y_{k}^{1}(t)}, v(t) \equiv \frac{c_{2}^{1}(t)}{y_{c}^{2}(t)} \rightarrow p(t)=\frac{v(t)}{1-u(t)}\left(\frac{\tilde{k}^{2}(t)}{\tilde{k}^{1}(t)}\right)^{\varphi}
$$

Interest rates of countries are obtained by proceeding as in the autarky situation:

$$
\begin{aligned}
& r^{1}(t)=\varphi e^{\gamma t}\left(\tilde{k}^{1}(t)\right)^{\varphi-1}-\delta+\frac{\dot{p}(t)}{p(t)}-\gamma, \\
& r^{2}(t)=\frac{1}{p(t)} \varphi e^{\gamma t}\left(\tilde{k}^{2}(t)\right)^{\varphi-1}-\delta+\frac{\dot{p}(t)}{p(t)}-\gamma,
\end{aligned}
$$

The long run equilibrium of the world economy is a BGP in which capital and consumption in both countries grow at a constant rate, and proportions $u(t)$ and $v(t)$ remain constant over time. From the law of motion of capital of countries evaluated over the BGP it follows that $\tilde{k}^{1}(t) / \tilde{k}^{2}(t)=u /(1-u)$. Several results can be derived from this relationship between capitals. First, long run growth rates of countries are identical to country 1's in autarky:

$$
\theta=\frac{\gamma}{1-\varphi}, \quad \theta=\theta_{\tilde{k}}^{i}=\theta_{\tilde{y}_{k}}^{i}, \varphi \theta=\theta_{c}^{i}=\theta_{y_{k}}^{i}, i=1,2
$$


Second, interest rate of countries equalize at long run and hence $\tilde{k}^{1}(t) / \tilde{k}^{2}(t)=v /(1-u)$ and $u=v$. Therefore, trade does not lead to wage equalization among countries. Third, gross world income is split among country 1 and 2 in the proportions $u$ and $1-u$, respectively. Lastly, the price of a physical unit of capital is constant, while the price per quality unit strictly decreases over time.

The value of $u$ is obtained from the law of motion of capital of either country 1 or 2 , the Euler equation and long run growth rates, and coincides with that in (23). Thus, international relative prices over the BGP are:

$$
\begin{aligned}
& p=\left(\frac{u}{1-u}\right)^{1-\varphi}, \bar{p}(t)=\frac{1}{e^{\gamma t}}\left(\frac{u}{1-u}\right)^{1-\varphi}, \\
& \text { where } u=\frac{\varphi(\gamma+(1-\varphi) \delta)}{\sigma \varphi \gamma+(1-\varphi)(\rho+\delta+\gamma)} \text {. }
\end{aligned}
$$

The comparison between autarky prices in expressions (20) and (24), and international prices over the BGP in (28) reveals that trade at long run will be characterised by complete specialization of countries only in the case that $u \geq 1 / 2$ :

$$
\begin{aligned}
& \bar{p}^{1}(t) \leq \bar{p}(t) \text { if } \frac{\varphi(\gamma+(1-\varphi) \delta)}{\sigma \varphi \gamma+(1-\varphi)(\rho+\delta+\gamma)} \geq \frac{1}{2}, \\
& \bar{p}^{2}(t)>\bar{p}(t) .
\end{aligned}
$$

Country 2 will always eventually completely specialize in the production of consumption good. However, country 1 will completely specialize only if its share in gross world income is greater than or equal to a half.

A conclusion from the results in this subsection is that country 2 imports sustained growth simply by trading. The improvement in country 2's terms of trade constitutes the 
diffusion mechanism. This finding comes out from differentiating country 2' interest rate over the BGP with respect to time:

$$
r^{2}=\frac{1}{\bar{p}(t)} \varphi\left(\tilde{k}^{2}(t)\right)^{\varphi-1}-\delta-\gamma \rightarrow \frac{\dot{\tilde{k}}^{2}(t)}{\tilde{k}^{2}(t)}=-\frac{1}{1-\varphi} \frac{\dot{\bar{p}}(t)}{\bar{p}(t)}=\frac{\gamma}{1-\varphi}
$$

It is obvious from expressions (28) and (30) that growth is generated by an improvement in the terms of trade of country 2 . The consumption good is increasingly expensive in international markets, which prevents the value of the marginal productivity of capital from falling in country 2, in spite of diminishing marginal productivity of capital. Thus, free trade is beneficial for country 2 because it permits an increase in real income and welfare. However, the remarkable benefit here is that country 2 is allowed to sustainably grow.

A second conclusion arises from this subsection, namely the crucial importance of considering quality-adjusted international prices. The omission or mistreatment of quality changes may lead to inaccurate conclusions regarding the mechanism through which trade operates in transmitting growth. If quality changes in the model were ignored, countries' "terms of trade" $p(t)$ would be constant in the long run, and exports and imports in quantity units would grow at the same rate $\varphi \theta$. The observation of those facts would lead to the wrong conclusion that openness impacts growth through the trade volume. A correct treatment of relative quality changes would show that country 2's terms of trade $\bar{p}(t)$ permanently improve, and its exports in quality units grow at a lower rate $(\varphi \theta)$ than its quality-adjusted imports $(\theta)$. It is obvious that country 2's trade volume continuously increases, but this is due to the time evolution of the terms of trade. 


\subsection{Trade Equilibrium under Incomplete Specialization}

Trade will be characterised by incomplete specialization if the condition in (29) does not hold. In this case, country 1 produces both capital and consumption good, exports the first good and imports the latter one. Country 2 only produces the good of consumption and, consequently, the firm's problem in capital good does not apply. Therefore, the competitive equilibrium of the world economy implies that $y_{k}^{1}(t)=I_{k}^{1}(t)+I_{c}^{1}(t)+I_{c}^{2}(t)$, $y_{c}^{1}(t)=c_{1}^{1}(t)$ and $y_{c}^{2}(t)=c_{2}^{1}(t)+c_{2}^{2}(t)$. The trade balance of countries must also be in equilibrium.

Since country 1 produces both goods, resources must be allocated among sectors. The same steps followed in the autarky case permit to show that the resources allocation is identical to that in (19), $p(t)$ and $\bar{p}(t)$ coincide with country 1's autarky prices in (20), and interest rates of countries are equal to those in (26), but with $p(t)=1$.

Considering exported-imported proportions of goods defined in (25) and the above results, the external equilibrium condition can be rewritten to obtain a relation between countries’ capital stocks:

$$
p(t)=\frac{v(t)}{1-u(t)} \frac{1}{l^{1}(t)}\left(\frac{\tilde{k}^{2}(t)}{\tilde{k}^{1}(t)}\right)^{\varphi}=1
$$

The long run equilibrium of the world economy is again a BGP, in which capital and consumption in both countries grow at a constant rate, and $\kappa^{1}(t), l^{1}(t), u(t)$ and $v(t)$ hold constant over time. From the requirement of constant interest rates at long run, it follows that the growth rates of countries are the same as those in (27). The equalization 
of interest rates implies that $\tilde{k}^{1}(t)=\tilde{k}^{2}(t)$ and, from (31), that $v=(1-u) I^{1}$. The fact that capital stocks become equal in the long run also implies that wage equalizes among countries. The value of $u$ is obtained using the laws of motion of capital of both countries. The value of $l^{1}$ comes from the law of motion of capital of either country 1 or 2 and the Euler equation. The next expression contains these values:

$$
u=\frac{1}{2}, l^{1}=\frac{2 \varphi(\gamma+(1-\varphi) \delta)}{\sigma \varphi \gamma+(1-\varphi)(\rho+\delta+\gamma)}, v=l^{1}(1-u)
$$

Over the BGP all relative prices equalize among countries and, hence, the long run equilibrium replicates the equilibrium of a fully integrated world economy. In addition, the trade situation under incomplete specialization leads to countries convergence in per capita income. The previous findings permit to write gross world income (GWI) and gross domestic income of country 1 and $2\left(G D I^{1}\right.$ and $\left.G D I^{2}\right)$ as:

$$
\begin{aligned}
& G W I \rightarrow \bar{p}(t) e^{\gamma t} y_{k}(t)+y_{c}(t)=\left(\tilde{k}^{1}(t)\right)^{\varphi}+\left(\tilde{k}^{2}(t)\right)^{\varphi}, \\
& G D I^{1} \rightarrow \bar{p}(t) e^{\gamma t} y_{k}^{1}(t)+y_{c}^{1}(t)=l^{1}\left(\tilde{k}^{1}(t)\right)^{\varphi}+\left(1-l^{1}\right)\left(\tilde{k}^{1}(t)\right)^{\varphi}, \\
& G D I^{2} \rightarrow y_{c}^{2}=\left(\tilde{k}^{2}(t)\right)^{\varphi},
\end{aligned}
$$

After imposing $\tilde{k}^{1}(t)=\tilde{k}^{2}(t)$ in (33), it becomes clear that countries' shares in GWI are equal to one half. The world production of consumption good, $y_{c}(t)$, is also equally distributed among country 1 and 2:

$$
\begin{aligned}
& c_{1}^{1}(t)+c_{2}^{1}(t)=\left(1-l^{1}\right)\left(\tilde{k}^{1}(t)\right)^{\varphi}+v\left(\tilde{k}^{2}(t)\right)^{\varphi}, c_{2}^{2}(t)=(1-v)\left(\tilde{k}^{2}(t)\right)^{\varphi}, \\
& \frac{c_{1}^{1}(t)+c_{2}^{1}(t)}{y_{c}(t)}=\frac{1-l^{1}+v}{2-l^{1}}=\frac{1}{2}, \frac{c_{2}^{2}(t)}{y_{c}(t)}=\frac{1-v}{2-l^{1}}=\frac{1}{2} .
\end{aligned}
$$


Since all factor inputs in country 2 are devoted to produce consumption good and labour is a non-reproducible factor, both factor allocation and export decision in country 1 will depend on countries' relative amounts of capital. If country 1's capital stock starts being higher than country 2's, then during the transitional period the return to capital will

be lower in the first economy than in latter one. Consequently, the proportions $l^{1}(t)$ and $u(t)$ are initially low, and raise as country 2 accumulates capital and the gap between interest rates narrows. Incentives to modify factor allocation and export decision in country 1 cease to exist when $\tilde{k}^{1}(t)=\tilde{k}^{2}(t)$, that is, when prices of both countries equalize. Over the BGP, imports from country 2 allow country 1 to double the proportion of labour and capital to produce capital good with respect to the autarky situation.

Therefore, the conclusion is again that free trade propagates permanent growth to country 2. The explanation for this result is the same as in the case of complete specialization. Lastly, convergence in per capita income comes out as a third benefit that country 2 obtains from free trade.

\section{Conclusion}

This paper has shown that a stagnant economy can overcome decreasing returns to capital accumulation and sustainably grows if its terms of trade permanently increase. The continuous improvement in the quality of imported capital goods relative to exported consumption goods is the reason why this occurs. Thus, the effects of trade on growth operate through relative prices. Moreover, countries converge in per capita income if trade is characterised by incomplete specialisation. 
Three main conclusions arise from these findings. First, terms of trade movements can act as an engine of growth for stagnant economies. The existence of mechanisms to absorb foreign technological progress is not necessary for the transmission of sustained growth to take place, since technical advances are embodied in imported inputs. Second, to properly adjust the terms of trade for quality changes of imported-exported goods is crucial for identifying the channels through which trade impacts growth. In this sense, the omission or mistreatment of quality changes might lead to the wrong conclusion that trade affects growth through trade volume, instead of through relative prices. Lastly, openness may emerge as an important force leading to countries convergence in per capita income, even though poor economies do not possess an own source of permanent growth. Therefore, the traditional close-economy approach for the study of convergence should be reconsidered.

As said above, the identification of the terms of trade movements as an engine of growth requires of quality-adjusted international prices. Though some public statistical agencies, as the American BLS, have made a considerable effort in providing researchers with quality-adjusted prices, the available datasets do not include information for developing countries. This statistical information would open broad avenues for future empirical and theoretical research on the role of terms of trade movements in promoting growth.

\section{References}

Athukorala, Prema-chandra, (1993), “Manufactured Exports from Developing Countries and Their Terms of Trade: A Reexamination of the Sarkar-Singer Results,” World Development, 21(10), October, 1607-13. 
Athukorala, Prema-chandra, (1998), Trade Policy Issues in Asian Development, London and New York: Routledge.

Athukorala, Prema-chandra, (2000), "Manufactured Exports and Terms of Trade of Developing Countries: Evidence from Sri Lanka,” Journal of Development Studies, 36(5), June, 89-104.

Barro, Robert and Xavier Sala-i-Martin, (1995). Economic Growth, New York: McGraw Hill.

Ben-David, Dan and Ayal Kimhi, (2004), "Trade and the Rate of Income Convergence,” Journal of International Trade and Economic Development, 13(4), December, 419-41.

Ben-David, Dan and Micharl B. Loewy, (2003), "Trade and the Neoclassical Growth Model,” Journal of Economic Integration, 18(1), March, 1-16.

Coe, David T., Elhanan Helpman, and Alexander W. Hoffmaister, (1997), "North-South R\&D Spillovers,” Economic Journal, 107(440), January, 134-49.

Cummins, Jason G., and Giovanni L. Violante, (2002), “Investment-Specific Technical Change in the United States (1947-2000): Measurement and Macroeconomic Consequences,” Review of Economic Dynamics, 5(2), April, 243-84.

Diewert, W. Erwin and Catherine J. Morrison, (1986), “Adjusting Output and Productivity Indexes for Changes in the Terms of Trade,” Economic Journal, 96(383), September, 659-79.

Fan, C. Simon, (2004), “Quality, Trade and Growth,” Journal of Economic Behavior and Organization, 55(2), October, 271-91. 
Greenwood, Jeremy, Zvi Hercowitz, and Per Krusell, (1997), “Long-Run Implications of Investment-Specific Technological Change,” American Economic Review, 87(3), June, $342-62$.

Harrison, Ann, (1996), “Openness and Growth: A Time Series, Cross Country Analysis for Developing Countries,” Journal of Development Economics, 48(2), March, 41947.

Hulten, Charles R., (1992), “Growth Accounting when Technical Change is Embodied in Capital,” American Economic Review, 82(4), September, 964-80.

Hwang, Jason and Jeffrey G. Williamson, (2003), "The Terms of Trade and Economic Growth in the Periphery, 1870-1938,” NBER Working Paper No 9940.

Jones, Charles I., (1994), “Economic Growth and the Relative Price of Capital,” Journal of Monetary Economics, 34(3), December, 359-82.

Keller, Wolfgang, (2002), "Trade and the Transmission of Technology,” Journal of Economic Growth, 7(1), March, 5-24.

Keller, Wolfgang, (2004), "International Technology Diffusion," Journal of Economic Literature, 42(3), September, 752-82.

Kohli, Ulrich, (2004), "Real GDP, Real Domestic Income, and the Terms-of-Trade Changes,” Journal of International Economics, 62(1), January, 83-106.

Lee, Jong-Wha, (1995), “Capital Goods Imports and Long-Run Growth,” Journal of Development Economics, 48(1), October, 91-110.

Murphy, Kevin M. and Andrei Shleifer, (1997), “Trade and Quality,” Journal of Development Economic, 53(1), June, 1-15. 
Rivera-Bátiz, Luis and Paul M. Romer, (1991), “Economic Integration and Endogenous Growth,” Quarterly Journal of Economics, 106(2), May, 531-55.

Sakellaris, Plutarchos and Daniel J. Wilson, (2004), “Quantifying Embodied Technical Change,” Review of Economic Dynamics, 7(1), January, 1-26.

Sarkar, Prabirjit and Hans W. Singer, (1991), "Manufactured Exports of Developing Countries and Their Terms of Trade Since 1965,” World Development, 19(4), April, $330-40$.

Solow, Robert, (1960), "Investment and Technical Progress,” in Kenneth J. Arrow, Samuel Karlin, and Patrick Suppes (eds.), Mathematical Methods in Social Sciences, Stanford, C.A.: Stanford University Press.

U.S. Department of Labor (Bureau of Labor Statistics), International Price Program, http://www.bls.gov/mxp/home.htm.

\section{Appendix A}

This appendix describes the steps to solve the autarky equilibrium of country 1 . The description concerning country 2' equilibrium is omitted.

The competitive equilibrium requires that markets in the economy clear. The clearing conditions for final and capital good markets appeared in the text. The clearing condition of labour market has been already introduced in the model. If these markets clear, then equity market also clears, $a^{i}(t)=\Pi_{k}^{i}(t)+\Pi_{c}^{i}(t)$. The fulfilment of the last condition follows from differentiating the value of firms at $t$, adding up them, and introducing the other clearing conditions: 


$$
\begin{aligned}
& \overbrace{\dot{\Pi}_{k}^{1}(t)+\dot{\Pi}_{c}^{1}(t)}^{\dot{a}^{1}(t)}=r^{1}(t) \overbrace{\left(\Pi_{k}^{1}(t)+\Pi_{c}^{1}(t)\right)}^{a^{1}(t)}- \\
& p^{1}(t) y_{k}^{1}(t)+p^{1}(t) \underbrace{\left(I_{k}^{1}(t)+I_{c}^{1}(t)\right)}_{y_{k}^{1}(t)}+\underbrace{w^{1}(t) l^{1}(t)+w^{1}(t)\left(1-l^{1}(t)\right)}_{w^{1}(t)}-\underbrace{y_{c}^{1}(t)}_{c^{1}(t)} .
\end{aligned}
$$

It also holds that the sum of firms' values is equal to the value of total capital, $\bar{p}^{1}(t) \tilde{k}^{1}(t)=\Pi_{k}^{1}(t)+\Pi_{c}^{1}(t)$, and that $\vartheta^{1}(0)=\bar{p}^{1}(0)$. This result can be easily proven proceeding as Barro and Sala (1995: 120).

The differentiation of expressions (11) and (14) respect to time yields:

$$
r_{k}^{i}(t)=-\frac{\dot{\lambda}_{k}^{i}(t)}{\lambda_{k}^{i}(t)}+\frac{\dot{p}^{1}(t)}{p^{1}(t)}-\frac{\dot{\tilde{q}}_{k}^{1}(t)}{\tilde{q}_{k}^{1}(t)}, r_{c}^{i}(t)=-\frac{\dot{\lambda}_{c}^{i}(t)}{\lambda_{c}^{i}(t)}+\frac{\dot{p}^{1}(t)}{p^{1}(t)}-\frac{\dot{\tilde{q}}_{k}^{1}(t)}{\tilde{q}_{k}^{1}(t)}
$$

Expression (18) comes from plugging (11) into (12), and (14) into (15), and introducing the resulting expressions into (A.2).

The Euler equation is obtained differentiating (16) respect to time and plugging (17). This equation evaluated over the BGP permits to get:

$$
\frac{\varphi \gamma}{1-\varphi}=e^{\gamma t}\left(\tilde{k}^{1}(t)\right)^{\varphi-1}-\delta-\gamma \rightarrow e^{\gamma t}\left(\tilde{k}^{1}(t)\right)^{\varphi-1}=\frac{\sigma \varphi \gamma+(1-\varphi)(\rho+\delta+\gamma)}{\varphi(1-\varphi)}
$$

Adding up (5) and (6) and evaluating the resulting expression over the BGP allow obtaining the value for $l^{1}=\kappa^{1}$ in (23):

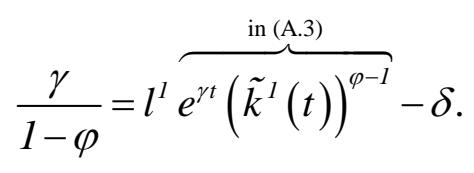

Lastly, the transversality conditions can be rewritten as: 


$$
\frac{\dot{\lambda}_{k}^{1}(t)}{\lambda_{k}^{1}(t)}+\frac{\dot{\tilde{k}}_{k}^{1}(t)}{\tilde{k}_{k}^{1}(t)}<0, \frac{\dot{\lambda}_{c}^{1}(t)}{\lambda_{c}^{1}(t)}+\frac{\dot{\vec{k}}_{c}^{1}(t)}{\tilde{k}_{c}^{1}(t)}<0,-\rho+\frac{\dot{\mu}^{1}(t)}{\mu^{1}(t)}+\frac{\dot{a}^{1}(t)}{a^{1}(t)}<0 .
$$

Expressions (A.2), (17) and (22), and the long-run value for interest rate permit to show that the fulfilment of (A.5) requires that:

$$
\theta_{c}^{1}<r^{1} \rightarrow(1-\sigma) \frac{\varphi \gamma}{1-\varphi}-\rho<0 .
$$

Hence, the usual condition that at long run interest rate must be greater than the growth rate of consumption must hold in order for discounted utility to be bounded. The fulfilment of (A.6) ensures that the value in (23) is smaller than one, that is, $\kappa^{1}=l^{1} \in(0,1)$.

\section{Appendix B}

This appendix concentrates on some details on the calculations of trade equilibrium under complete specialization. Those calculations that can be easily derived from the explanations in the text and in the previous appendix are omitted.

The competitive equilibrium of the world economy implies the clearing conditions in the text are satisfied and, hence, that $a^{1}(t)=\Pi_{k}^{1}(t)$ and $a^{2}(t)=\Pi_{c}^{2}(t)$. Proceeding as in the previous appendix, it is obtained that:

$$
\begin{aligned}
& \overbrace{\dot{\Pi}_{k}^{1}(t)}^{\dot{a}^{1}(t)}=r^{1}(t) \overbrace{\Pi_{k}^{1}(t)}^{a^{1}(t)}+w^{1}(t)-\overbrace{\left(p(t) y_{k}^{1}(t)-p(t) I_{k}^{1}(t)\right)}^{c_{2}^{1}(t)}, \\
& \overbrace{\dot{\Pi}_{c}^{2}(t)}^{\dot{a}^{2}(t)}=r^{2}(t) \overbrace{\Pi_{c}^{2}(t)}^{a^{2}(t)}+w^{2}(t)-\overbrace{\left(y_{c}^{2}(t)-p(t) I_{c}^{1}(t)\right)}^{c_{2}^{2}(t)} .
\end{aligned}
$$


Considering the definitions in (25), the accumulation of capital of countries can be rewritten as:

$$
\frac{\dot{\tilde{k}}^{1}(t)}{\tilde{k}^{1}(t)}=u \frac{\tilde{y}_{k}^{1}(t)}{\tilde{k}^{1}(t)}-\delta, \frac{\dot{\tilde{k}}^{2}(t)}{\tilde{k}^{2}(t)}=(1-u) \frac{\tilde{y}_{k}^{1}(t)}{\tilde{k}^{2}(t)}-\delta .
$$

Since the growth rates of capital equalize at long run, it follows that $u=v$.

\section{Appendix C}

This appendix explains the derivation of some results in subsection IV.2. As in Appendix B, only some calculations will be described. Market clearing conditions imply that:

$$
\begin{aligned}
& \overbrace{\dot{\Pi}_{k}^{1}(t)+\dot{\Pi}_{c}^{1}(t)}^{\dot{a}^{1}(t)}=r^{1}(t) \overbrace{\left(\Pi_{k}^{1}(t)+\Pi_{c}^{1}(t)\right)}^{a^{1}(t)}+\overbrace{w^{1}(t) l^{1}(t)+w^{1}(t)\left(1-l^{1}(t)\right)}^{w^{1}(t)}- \\
& \underbrace{\left(p(t) y_{k}^{1}(t)-p(t)\left(I_{k}^{1}(t)+I_{c}^{1}(t)\right)\right)}_{c_{2}^{1}(t)}-\underbrace{y_{c}^{1}(t)}_{c_{1}^{1}(t)},
\end{aligned}
$$

and the second expression in (B.1).

The value of $u$ is obtained by proceeding as in Appendix B, but it is first necessary to add up (5) and (6) for country 1. The long run value of $e^{\gamma t}\left(\tilde{k}^{1}(t)\right)^{\varphi-1}$ is calculated using the Euler equation, and coincides with that in (A.3). Given $u, e^{\gamma t}\left(\tilde{k}^{1}(t)\right)^{\varphi-1}$ and the result that $\theta_{\tilde{k}}^{1}=\theta_{\tilde{k}}^{2}$, the motion law of capital of either country 1 or 2 permits to solve for $l^{1}=\kappa^{1}:$

$$
\frac{\dot{\tilde{k}}^{1}(t)}{\tilde{k}^{1}(t)}=u l^{1} \frac{\tilde{y}_{k}^{1}(t)}{\tilde{k}^{1}(t)}-\delta, \frac{\dot{\tilde{k}}^{2}(t)}{\tilde{k}^{2}(t)}=(1-u) l^{1} \frac{\tilde{y}_{k}^{1}(t)}{\tilde{k}^{2}(t)}-\delta
$$

